\title{
Pitfalls with the use of enhancement ratios or normalized excess mixing ratios measured in plumes to characterize pollution sources and aging
}

\author{
R. J. Yokelson ${ }^{1}$, M. O. Andreae ${ }^{2,3}$, and S. K. Akagi ${ }^{1}$ \\ ${ }^{1}$ University of Montana, Department of Chemistry, Missoula, MT 59812, USA \\ ${ }^{2}$ Biogeochemistry Department, Max Planck Institute for Chemistry, Mainz 55020, Germany \\ ${ }^{3}$ Scripps Institution of Oceanography, University of California San Diego, La Jolla, CA 92093, USA \\ Correspondence to: R. J. Yokelson (bob.yokelson@umontana.edu)
}

Received: 26 March 2013 - Published in Atmos. Meas. Tech. Discuss.: 29 April 2013

Revised: 1 July 2013 - Accepted: 18 July 2013 - Published: 28 August 2013

\begin{abstract}
Normalized excess mixing ratios (NEMRs), also known as enhancement ratios, are a common way to characterize plumes of pollution in atmospheric research. As single-source pollutant plumes disperse in the atmosphere, they are diluted by mixing with the adjacent background air. Changes in the composition of this background air can cause large changes to the NEMR that is subsequently measured by remote-sensing, airborne, or ground-based instruments. This scenario is common when boundary layer plumes enter the free troposphere and could also impact long-range transport or plumes near the top of the troposphere. We provide a context for these issues and an example showing that neglect of this effect could lead to serious errors in data interpretation.
\end{abstract}

\section{Introduction}

Excess mixing ratios in single-source plumes (hereinafter "plumes") from fossil fuel or biomass burning sources can be calculated as the mixing ratio of species $X$ in the plume minus the mixing ratio of species $X$ in background air. Commonly denoted $\Delta X$, excess mixing ratios typically decrease with plume age due to dilution. The normalized excess mixing ratio (NEMR) (Andreae et al., 1988; Hobbs et al., 2003), or enhancement ratio (EnR) (Lefer et al., 1994), can be calculated for any species $X$ by dividing $\Delta X$ by the excess mixing ratio of a reference species $Y$ (denoted as $\Delta Y$ ) measured in the same sample as $X$. Species $Y$ is usually selected as a relatively stable plume "tracer", such as carbon dioxide $\left(\mathrm{CO}_{2}\right)$ or carbon monoxide $(\mathrm{CO})$, to normalize for dilution. The NEMR, or EnR, is denoted as $\Delta X / \Delta Y$ and can be measured in several ways. When grab samples are made in both the plume and background air, $\Delta X / \Delta Y$ can be computed from $\left(X_{\text {plume }}-X_{\text {background }}\right) /\left(Y_{\text {plume }}-Y_{\text {background }}\right)$. Alternatively, as the composition of the background air is not always known (e.g., for airborne measurements in extensive plumes), $\Delta X / \Delta Y$ can be obtained as the regression slope between multiple measurements of $X$ and $Y$ during plume passages. In this note we discuss some limitations to the use of NEMRs to characterize source emissions and plume aging.

\section{Discussion and conclusions}

When $\Delta X / \Delta Y$ is measured at the source, it is equivalent to an initial molar emission ratio (ER) at the time of measurement. For a single source with a fixed ER (i.e., one that does not change with time) that is also mixed with a fixed background (i.e., $X$ and $Y$ are unchanging in the background air), the NEMR (or EnR) will remain equal to the ER despite dilution, as long as there is no photochemical or other production or loss impacting $X$ or $Y$. Thus, for a fixed source mixed with a fixed background, comparison of NEMR or EnR with ER can reveal changes due to (photo)chemistry during plume aging (Akagi et al., 2012). Under these conditions the agedependent NEMRs and EnRs are powerful tools to measure actual rates of chemical transformations in the atmosphere, until dilution proceeds to the point where $\Delta X$ or $\Delta Y$ approaches the uncertainty in the $X$ and $Y$ values in the plume 
Table 1. The effect of various dilution scenarios on the calculation of the normalized excess mixing ratio (NEMR).

\begin{tabular}{|c|c|c|c|c|c|c|c|}
\hline \multicolumn{2}{|c|}{$\begin{array}{l}\text { Mixing ratios* } \\
\quad \text { (plume) }\end{array}$} & \multicolumn{2}{|c|}{$\begin{array}{l}\text { Mixing ratios* } \\
\text { (background, bg) }\end{array}$} & \multicolumn{2}{|c|}{$\begin{array}{l}\text { Excess mixing } \\
\text { ratios* }\end{array}$} & \multirow[t]{2}{*}{ NEMR } & \multirow[t]{2}{*}{ Observations } \\
\hline \multicolumn{6}{|c|}{ Long-range transport } & & \\
\hline $\mathrm{CO}_{2}$ & $\mathrm{CO}$ & $\mathrm{bgCO}_{2}$ & $\mathrm{bgCO}$ & $\Delta \mathrm{CO}_{2}$ & $\Delta \mathrm{CO}$ & $\Delta \mathrm{CO} / \Delta \mathrm{CO}_{2}$ & \\
\hline 1000.0 & 38.0 & 390 & 0.1 & 610.00 & 37.90 & 0.06 & Source sample emitted in location A \\
\hline 695.0 & 19.1 & 390 & 0.1 & 305.00 & 18.95 & 0.06 & \\
\hline 542.5 & 9.6 & 390 & 0.1 & 152.50 & 9.48 & 0.06 & Constant background scenario: the NEMR remains unchanged \\
\hline 466.3 & 4.8 & 390 & 0.1 & 76.25 & 4.74 & 0.06 & with each 50/50 source sample/background dilution (i.e., $1000 \mathrm{ppm}$ \\
\hline 404.5 & 0.8 & 400 & 0.3 & 4.53 & 0.49 & 0.11 & $\begin{array}{l}\text { Change bg conditions to location B: the NEMR changes when } \\
\text { the background mixing ratios are changed. }\end{array}$ \\
\hline \multicolumn{8}{|c|}{ Stratospheric/tropospheric mixing with no photochemistry assumed } \\
\hline $\mathrm{O}_{3}$ & $\mathrm{CO}$ & $\mathrm{bgO}_{3}$ & $\mathrm{bgCO}$ & $\Delta \mathrm{O}_{3}$ & $\Delta \mathrm{CO}$ & $\Delta \mathrm{O}_{3} / \Delta \mathrm{CO}$ & \\
\hline 0.06 & 0.125 & 0.05 & 0.1 & 0.01 & 0.025 & 0.40 & Source sample emitted in troposphere \\
\hline \multicolumn{8}{|c|}{ Boundary layer $(\mathrm{BL})$ entrainment in the free troposphere } \\
\hline $\mathrm{CO}_{2}$ & $\mathrm{H}_{2} \mathrm{O}$ & $\mathrm{bgCO}_{2}$ & $\mathrm{bgH}_{2} \mathrm{O}$ & $\Delta \mathrm{CO}_{2}$ & $\Delta \mathrm{H}_{2} \mathrm{O}$ & $\Delta \mathrm{H}_{2} \mathrm{O} / \Delta \mathrm{CO}_{2}$ & \\
\hline 1000 & 11000 & 390 & 10000 & 610 & 1000 & 1.64 & Source sample emitted in the BL \\
\hline 695 & 10500 & 390 & 10000 & 305 & 500 & 1.64 & $\begin{array}{l}\text { Boundary layer conditions: the NEMR remains unchanged with } \\
\text { each } 50 / 50 \text { source sample/background dilution in the BL. }\end{array}$ \\
\hline 537.5 & 5750 & 380 & 1000 & 157.5 & 4750 & 30.2 & $\begin{array}{l}\text { Change bg conditions from BL to free troposphere: the NEMR } \\
\text { changes when the background environment is changed. }\end{array}$ \\
\hline
\end{tabular}

* Mixing ratios in ppm.

or background. This ideal situation is easily confirmed by simple calculations, as shown in Table 1 . For example, if a source sample of a plume contains $1000 \mathrm{ppm}$ of $\mathrm{CO}_{2}$ and $38 \mathrm{ppm}$ of $\mathrm{CO}$ and the background air has $390 \mathrm{ppm}$ of $\mathrm{CO}_{2}$ and $0.1 \mathrm{ppm}$ of $\mathrm{CO}$, the $\Delta \mathrm{CO} / \Delta \mathrm{CO}_{2}$ value is 0.0621 . If the plume is repeatedly mixed $(1: 1$, in the case presented in Table 1) with the same background values, $\Delta \mathrm{CO} / \Delta \mathrm{CO}_{2}$ is conserved as shown in the top scenario in Table 1.

However, consider the case where, after initially mixing with the ambient background air, the plume is then mixed with background air that, for whatever reason, has different values for $\mathrm{CO}$ and $\mathrm{CO}_{2}$. This could occur for example as a result of transport over a different underlying ecosystem, further convective transport, or atmospheric shear. In this case it is easily shown that $\Delta \mathrm{CO} / \Delta \mathrm{CO}_{2}$ is no longer conserved (last line of the top scenario in Table 1). This effect applies to all $\Delta X / \Delta Y$ pairs if $X$ and $Y$ are not constant in the background. The case where the background air changes is potentially problematic, especially for groundbased or airborne measurements of plumes aged more than approximately one day; given that it may not be physically possible to characterize $X$ and $Y$ in the background along the entire plume trajectory. Actually, multi-step mixing happens in many cases since, for most sources, the emissions first mix extensively with local boundary layer air before the plume rises to the level of neutral buoyancy, which can be in the free troposphere. Following plume rise to a free tropospheric "injection altitude", the plume mixes during horizontal transport with the air at that level, which often has very different trace gas composition from the boundary layer where the plume originated. In general, whenever a plume initially mixes in a relatively "dirty" boundary layer (containing fresh and aged pollution, high biogenic emissions, or water) and then enters a "cleaner" free troposphere, the excess mixing ratios and NEMRs can reflect differences between these layers, as shown in the bottom scenario of Table 1 . As a "real world" example, this is problematic with $\mathrm{CO}_{2}$ as the reference species, because the $\mathrm{CO}_{2}$ mixing ratios in the boundary layer can be tens of ppm higher than in the free troposphere, especially during the morning hours. For this reason, free tropospheric measurements of $\Delta X / \Delta Y$ made before noon and using $\mathrm{CO}_{2}$ as reference species are often unreliable (Guyon et al., 2005). Figure 1 illustrates this phenomenon using typical values for planetary boundary layer (PBL) and free troposphere (FT) mixing ratios of $\mathrm{CO}$ and $\mathrm{CO}_{2}$. In the morning there is a steep $\mathrm{CO}_{2}$ gradient between the PBL and the FT, yielding a completely unrealistic low value of $\Delta \mathrm{CO} / \Delta \mathrm{CO}_{2}$, while in the afternoon, convective mixing reduces the gradients in reference species and thereby reduces or eliminates this source of bias. We stress that this example is not intended to illustrate that all afternoon measurements or other reference species are immune to mixing effects. A 


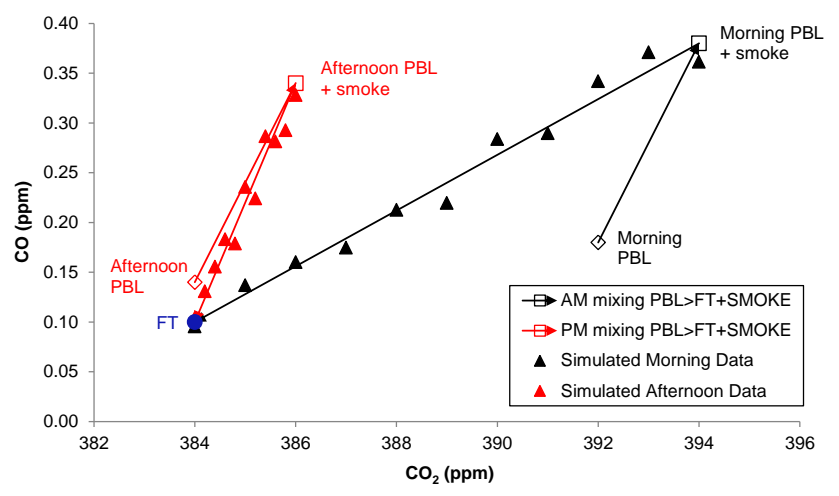

Fig. 1. A scenario encountered in the Amazon described in Andreae et al. (2012). The morning PBL has mixing ratios of $392 \mathrm{ppm} \mathrm{CO}_{2}$ and $0.18 \mathrm{ppm} \mathrm{CO}$ (shown by the black diamond). A fire burning in the morning hours with a $\Delta \mathrm{CO} / \Delta \mathrm{CO}_{2}$ ER of 0.1 adds $2 \mathrm{ppm} \Delta \mathrm{CO}_{2}$ and $0.2 \mathrm{ppm} \triangle \mathrm{CO}$ to the morning PBL, creating a plume with the composition indicated by the black square ( $394 \mathrm{ppm} \mathrm{CO}_{2}, 0.38 \mathrm{ppm}$ $\mathrm{CO})$. This plume is lofted into the free troposphere, which has the composition indicated by the blue circle $\left(384 \mathrm{ppm} \mathrm{CO}_{2}, 0.1 \mathrm{ppm}\right.$ $\mathrm{CO}$ ), and mixes with this FT air. The black triangles simulate the data that would be obtained (with $10 \%$ "noise" added) as an aircraft flies through this plume acquiring "real time" data as the plume dilutes. From the FT aircraft data, an erroneous ER of 0.03, instead of the correct value of 0.1 , would be calculated as a result of the error introduced by multiple mixing with different air masses. In the afternoon, the gradient between the PBL (red diamond, 384 ppm $\mathrm{CO}_{2}$ and $0.14 \mathrm{ppm} \mathrm{CO}$ ) and the FT is reduced. Adding the same amount of smoke, with the same composition as from the morning fire, now creates a plume with the composition indicated by the red square (386 ppm CO $2,0.34 \mathrm{ppm} \mathrm{CO}$ ). When the afternoon plume is lofted into the FT, which has the same composition as in the morning, the research aircraft would obtain data simulated by the red triangles. An ER of 0.12 would be calculated from these data, much closer to the true value of 0.1 .

study-specific analysis is required. A similar caution about mixing between layers applies as plumes in the free troposphere approach the tropopause or stratosphere, where background values change dramatically for many species such as $\mathrm{O}_{3}$ and $\mathrm{H}_{2} \mathrm{O}$ (see example in the middle of Table 1). In fact, Nowak et al. (2004) describe a very interesting case where Asian anthropogenic emission plumes mixed with both free troposphere and stratospheric air during transport across the Pacific. While many important NEMRs were meaningful, the mixing was too complex to allow a confident partitioning of the anthropogenic and stratospheric contributions to the observed $\Delta \mathrm{O}_{3} / \Delta \mathrm{CO}$ NEMRs. In general, the distortion of the NEMR depends both on the gradient between layers and on how concentrated the plume is when it switches layers; with high plume concentrations diminishing the distortion.

In theory, remote sensing studies of plumes could sometimes use their broader coverage to account for changes in the adjacent background air even in highly aged plumes, but to our knowledge this has not been attempted. Many authors have previously considered the effect of mixing in far more complex situations than we describe here, such as determining $\mathrm{OH}$ concentrations with "photochemical clocks" (e.g., reactive hydrocarbon ratios) in mixed-age, multi-source, continental-scale plumes where layers also mix and the plume is sampled at various downwind ages (McKeen et al., 1990; Wingenter et al., 1996; Rudolph and Czuba, 2000; Parrish et al., 2007). The effects we discuss may be implicitly or explicitly included in other work, and we make no claim of novelty. Here we simply remind the reader of an elementary process that can greatly change the measured value of the NEMR even for two inert species emitted by a single source. The effect can occur whenever plumes mix with two layers of the atmosphere that have different composition. Airborne, ground-based, or satellite measurements are frequently made only in one downwind region in plumes; or in any case, not directly at the source. When a concentration gradient is observed, this confirms mixing of two different air parcels, but if the origin of the two parcels that are mixing is not clearly established, then the interpretation of the NEMRs can be uncertain. However, even without explicit source samples or detailed knowledge of the mixing history, numerous published studies have equated the downwind NEMR to an ER or compared the downwind NEMR to available literature ER. In the latter case, a widespread tendency is to interpret any differences between the NEMR measured in an aged plume and the literature ER as the effects of aging, lack of aging, or errors in the literature ER. As discussed in detail elsewhere, comparing NEMR in aged plumes to literature average ER for variable phenomena is associated with high uncertainty (Andreae and Merlet, 2001; Akagi et al., 2011). This note is to remind authors that both variability in the possible source ER and simple mixing effects contribute to the uncertainty in comparisons of measured downwind NEMRs with literature ER. Thus, both variability and mixing effects should be considered when interpreting a measured NEMR as a probe of aging or an ER.

Edited by: D. Riemer

\section{References}

Akagi, S. K., Yokelson, R. J., Wiedinmyer, C., Alvarado, M. J., Reid, J. S., Karl, T., Crounse, J. D., and Wennberg, P. O.: Emission factors for open and domestic biomass burning for use in atmospheric models, Atmos. Chem. Phys., 11, 4039-4072, doi:10.5194/acp-11-4039-2011, 2011.

Akagi, S. K., Craven, J. S., Taylor, J. W., McMeeking, G. R., Yokelson, R. J., Burling, I. R., Urbanski, S. P., Wold, C. E., Seinfeld, J. H., Coe, H., Alvarado, M. J., and Weise, D. R.: Evolution of trace gases and particles emitted by a chaparral fire in California, Atmos. Chem. Phys., 12, 1397-1421, doi:10.5194/acp-12-13972012, 2012.

Andreae, M. O. and Merlet, P.: Emission of trace gases and aerosols from biomass burning, Global Biogeochem. Cy., 15, 955-966, doi:10.1029/2000GB001382, 2001.

Andreae, M. O., Browell, E. V., Garstang, M., Gregory, G. L., Harriss, R. C., Hill, G. F., Jacob, D. J., Pereira, M. C., Sachse, G. W., 
Setzer, A. W., Silva Dias, P. L., Talbot, R. W., Torres, A. L., and Wofsy, S. C.: Biomass burning emissions and associated haze layers over Amazonia, J. Geophys. Res., 93, 1509-1527, 1988.

Andreae, M. O., Artaxo, P., Beck, V., Bela, M., Freitas, S., Gerbig, C., Longo, K., Munger, J. W., Wiedemann, K. T., and Wofsy, S. C.: Carbon monoxide and related trace gases and aerosols over the Amazon Basin during the wet and dry seasons, Atmos. Chem. Phys., 12, 6041-6065, doi:10.5194/acp-12-6041-2012, 2012.

Guyon, P., Frank, G. P., Welling, M., Chand, D., Artaxo, P., Rizzo, L., Nishioka, G., Kolle, O., Fritsch, H., Silva Dias, M. A. F, Gatti, L. V., Cordova, A. M., and Andreae, M. O.: Airborne measurements of trace gas and aerosol particle emissions from biomass burning in Amazonia, Atmos. Chem. Phys., 5, 29893002, doi:10.5194/acp-5-2989-2005, 2005.

Hobbs, P. V., Sinha, P., Yokelson, R. J., Christian, T. J., Blake, D. R., Gao, S., Kirchstetter, T. W., Novakov, T., and Pilewskie, P.: Evolution of gases and particles from a savanna fire in South Africa, J. Geophys. Res., 108, 8485, doi:10.1029/2002JD002352, 2003.

Lefer, B. L., Talbot, R. W., Harriss, R. C., Bradshaw, J. D., Sandholm, S. T., Olson, J. O., Sachse, G. W., Collins, J., Shipham, M. A., Blake, D. R., Klemm, K. I., Klemm, O., Gorzelska, K., and Barrick, J.: Enhancement of acidic gases in biomass burning impacted air masses over Canada, J. Geophys. Res., 99, 1721-1737, 1994.

McKeen, S. A., Trainer, M., Hsie, E. Y., Tallamraju, R. K., and Liu, S. C.: On the indirect determination of atmospheric $\mathrm{OH}$ radical concentrations from reactive hydrocarbon measurements, J. Geophys. Res., 95, 7493-7500, 1990.
Nowak, J. B., Parrish, D. D., Neuman, J. A., Holloway, J. S., Cooper, O. R., Ryerson, T. B., Nicks Jr., D. K., Flocke, F., Roberts, J. M., Atlas, E., de Gouw, J. A., Donnelly, S., Dunlea, E., Hübler, G., Huey, L. G., Schauffler, S., Tanner, D. J., Warneke, C., and Fehsenfeld, F. C.: Gas-phase chemical characteristics of Asian emission plumes observed during ITCT 2K2 over the eastern North Pacific Ocean, J. Geophys. Res., 109, D23S19, doi:10.1029/2003JD004488, 2004.

Parrish, D. D., Stohl, A., Forster, C., Atlas, E. L., Blake, D. R., Goldan, P. D., Kuster, W. C., and de Gouw, J. A.: Effects of mixing on evolution of hydrocarbon ratios in the troposphere, J. Geophys. Res., 112, D10S34, doi:10.1029/2006JD007583, 2007.

Rudolph, J., and Czuba, E.: On the use of isotopic composition measurements of volatile organic compounds to determine the "photochemical age" of an air mass, Geophys. Res. Lett., 27, 38653868, 2000.

Wingenter, O. W., Kubo, M. K., Blake, N. J., Smith Jr., T. W., Blake, D. R., and Rowland, F. S.: Hydrocarbon and halocarbon measurements as photochemical and dynamical indicators of atmospheric hydroxyl, atomic chlorine, and vertical mixing obtained during Lagrangian flights, J. Geophys. Res., 101, 4331-4340, 1996. 